\title{
CYSTIC ECHINOCOCCOSIS IN SLAUGHTERED CATTLE AND SHEEP FROM NORTH MACEDONIA
}

\author{
Ljubica Rashikj ${ }^{1}$, Aleksandar Cvetkovikj ${ }^{1}$, Martin Nikolovski², \\ Iskra Cvetkovikj ${ }^{1}$, Jovana Stefanovska ${ }^{1}$ \\ ${ }^{1}$ Veterinary Institute, Faculty of Veterinary Medicine - Skopje, Ss. Cyril and Methodius \\ University in Skopje, Lazar Pop-Trajkov 5-7, 1000 Skopje, North Macedonia \\ ${ }^{2}$ Institute for Reproduction and Biomedicine, Faculty of Veterinary Medicine - Skopje, \\ Ss. Cyril and Methodius University in Skopje, Lazar Pop-Trajkov 5-7, \\ 1000 Skopje, North Macedonia
}

Received 20 October 2021; Received in revised form 2 December 2021; Accepted 10 December 2021

\begin{abstract}
Cystic echinococcosis is a cosmopolitan zoonotic infection, commonly seen in areas where livestock and dogs are kept together. The objective of this study was to investigate the prevalence of echinococcosis in slaughtered cattle and sheep in North Macedonia and to evaluate the location and fertility/sterility rates of the cysts. A total of 302 slaughtered animals were examined with visual inspection, palpation, and incision of the internal organs in order to detect cysts. Microscopic examination was carried out to determine the presence of protoscoleces. The overall prevalence of echinococcosis in slaughtered cattle and sheep was $60 \%$. The presence of cysts increased with age in cattle. In both cattle and sheep, the most common affected organs were the liver and lungs infected with more than one cyst. The findings showed higher fertility rate in sheep which confirmed their role as the most important intermediate host. This study shows that North Macedonia is an endemic region, and serious control strategies should be implemented, with special emphasis on safety disposal of infected organs and anthelmintic treatment of the dogs.
\end{abstract}

Key words: Echinococcosis, North Macedonia, cattle, sheep, prevalence

\section{INTRODUCTION}

Cystic echinococcosis (CE) is an important parasitic zoonotic disease caused by the larval form of the taeniid tapeworm Echinococcus granulosus (1). According to the World Health Organization (WHO), echinococcosis is a neglected disease with worldwide distribution that needs prevention and control (2).

Carnivores (mainly canids) are definitive hosts for the adult tapeworm, while herbivores (mainly

Corresponding author: Asst. Res. Prof. Aleksandar Cvetkovikj, PhD E-mail address: acvetkovic@fvm.ukim.edu.mk

Present address: Veterinary Institute, Faculty of Veterinary Medicine -

Skopje, Ss. Cyril and Methodius University in Skopje, Lazar Pop-Trajkoy

5-7, 1000 Skopje, North Macedonia

Phone: +3892 3240740; Fax: +38923114619

Copyright: (C) 2022 Rashikj Lj. This is an open-access article published under the terms of the Creative Commons Attribution License which permits unrestricted use, distribution, and reproduction in any medium, provided the original author and source are credited.

Competing Interests: The authors have declared that no competing interests exist.

Available Online First: 17 January 2022

Published on: 15 March 2022

https://doi.org/10.2478/macvetrev-2022-0011 ruminants) and omnivores act as intermediate hosts that get infected by ingestion of infective tapeworm eggs that develop to the larval form metacestode located in the internal organs (3). The adult tapeworm lives in the small intestine of the definitive hosts, produces infective eggs that leave the host with feces, and contaminate the soil and the water, making the environment a potential risk for the human population (4). Canids get infected when they feed on offal from slaughtered domestic ruminants containing metacestodes. Humans, on the other hand, are an aberrant, dead-end host (5).

The fully developed metacestode is an unilocular spherical cyst, filled with liquid, consisting of an internal germinated layer and external elastic acellular laminated layer. Numerous protoscoleces are developed asexually in the inner lumen (6). The cyst that contains protoscoleces is called fertile, while the cyst that doesn't have protoscoleces is called sterile. Fertility of the cysts is very important when it comes to reviewing the epidemiology 
of echinococcosis and depends on host species (7). The target organ is the liver, followed by the lungs. Other organs that can be affected include the spleen, the kidneys, and the heart (8). Cysts grow slowly, no more than $1-5 \mathrm{~cm}$ every year, with no functional disorders of the organs and no clinical signs in the diseased animals (9). There is no reliable diagnostic method for live animals, therefore, the diagnosis of echinococcosis is based on post-mortem examination during slaughter (10).

Echinococcosis is endemic in many parts of the world, with very high prevalence in China, Central Asia, South America, North and East Africa, and Australia. In Europe, echinococcosis is present in the Mediterranean region and Southeastern countries (11).

Italy is a country with middle to high risk for echinococcosis, with a prevalence of $5-92.8 \%$ in sheep and 7.3-67.1\% in cattle (12). In Romania, the prevalence of echinococcosis is $32.34 \%$ in cattle and $49.87 \%$ in sheep (13). In Poland, the prevalence of echinococcosis in cattle is $0.007 \%$, while in sheep and goats is $18.7 \%$ (14). In Spain, echinococcosis is prevalent in $1.70 \%$ of cattle and $0.10 \%$ of sheep (15), while in France the prevalence of echinococcosis is quite low: $0.00004 \%$ in sheep and $0.00003 \%$ in cattle (16).

The prevalence of echinococcosis in the Balkan region is known in Kosovo ( $72 \%$ in cattle) (17), Bosnia and Herzegovina $(27.2 \%$ in cattle, $80.3 \%$ in sheep) (18), Albania (5-75\% in sheep and cattle) (19), Greece (33.3\% in sheep) (20), Bulgaria (5.1\% in cattle, $7.0 \%$ in sheep and $10.5 \%$ in goats) (21) and Serbia ( $1 \%$ in sheep, $2 \%$ in cattle) (22).

In North Macedonia echinococcosis is considered to be endemic. On the other hand, North Macedonia is the only country in the Balkan region with an unknown prevalence of echinococcosis and no published data (11). Hence, the aim of this study was to determine the slaughterhouse prevalence in cattle and sheep, the presence of cysts in different organs, and the fertility/sterility rate of the cysts. The data will provide reliable information about the domestic ruminants as potential infection sources for the dogs and the environmental contamination with echinococcus eggs.

\section{MATERIAL AND METHODS}

\section{Study animals and sampling methods/study design}

This study was conducted between July and October 2020 in four slaughterhouses. A total of 302 animals (234 cattle from 36 farms and 68 sheep from two farms) were examined for the presence of hydatid cysts in the visceral organs. The animals originated from 23 localities within 11 municipalities of the territory of North Macedonia.

\section{Ante-mortem examination}

During the antemortem examination, the animals were divided into three age categories ( $<2$ years, $2-5$ years, $>5$ years) and each animal was given an identification number. The sex, origin, and type (cattle or sheep) of each animal were also recorded.

\section{Post-mortem examination}

Visual inspection, palpation, and incision of the internal organs of the slaughtered animals was performed to detect hydatid cysts. The spleen and the kidneys were examined with palpation, while the lungs and the liver were examined with incision for better visualization of the possible presence of cysts. Detailed record was kept about the cyst number per organ and its location. The cysts were carefully removed from the infected organ and collected in a sterile cup under aseptic conditions and then transferred in an icebox to the Laboratory for Parasitology and Parasitic Diseases at the Faculty of Veterinary Medicine - Skopje for examination. Underdeveloped cysts were not included in this study.

\section{Laboratory examination}

As suggested by Daryani et al. (23), the cysts were classified as fertile if they contained liquid content with protoscoleces and sterile if they contained liquid content without protoscoleces. To assess the fertility of each cyst, the fluid was removed with a syringe and needle and was then transferred to a glass beaker. The cysts were washed with saline and the content was added to the corresponding glass beaker. The cyst content was poured into a $50 \mathrm{ml}$ conical centrifugation tube and centrifuged at $5000 \mathrm{rpm}$ for five minutes. After centrifugation, the supernatant was discarded and the sediment was analysed for the presence of protoscoleces under a stereomicroscope at $40 \mathrm{x}$ magnification. The wall of each cyst was cut open with a sterile scalpel blade and scissors and the germinative layer was removed and preserved in a cup with $70 \%$ ethanol.

\section{Statistical analysis}

The categorical data for each respective analysis were organized in contingency tables and 
were analysed with Pearson's Chi-square Test for Independence. Values were presented as percentage from the total specimen count in the corresponding groups. The significance level was set at $\mathrm{p}<0.05$.

\section{RESULTS}

A significantly higher number of positive cattle specimens were detected in the age group $>5$ years compared to the $<2$ and $2-5$ years groups $(64 \%, 37 \%$, and $36 \%$, respectively). The latter groups did not show significant difference in the number of positive specimens (Fig. 1A).
Despite that the 2-5 years age group in sheep had markedly higher value of positives, it was not significantly different compared to the $<2$ and $>5$ years age groups, which were also insignificantly different $(59 \%, 22 \%$, and $40 \%$, respectively) (Fig. 1B).

A significantly higher number of cattle lung and liver specimens were found with $>1$ cyst compared to specimens with 1 cyst ( $75 \%$ vs. $25 \%$ and $67 \%$ vs. $33 \%$, respectively) (Fig. 2A, B).

A significantly higher number of sheep lung and liver specimens were found with $>1$ cyst compared to specimens with 1 cyst (79 \% vs. $21 \%$ and $68 \%$ vs $32 \%$, respectively) (Fig. 2 C, D).
A

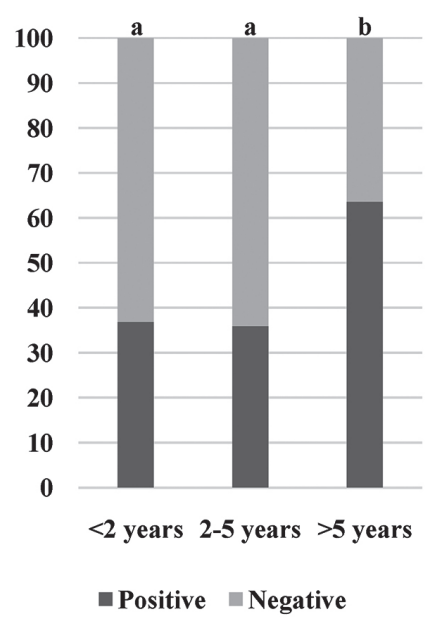

B

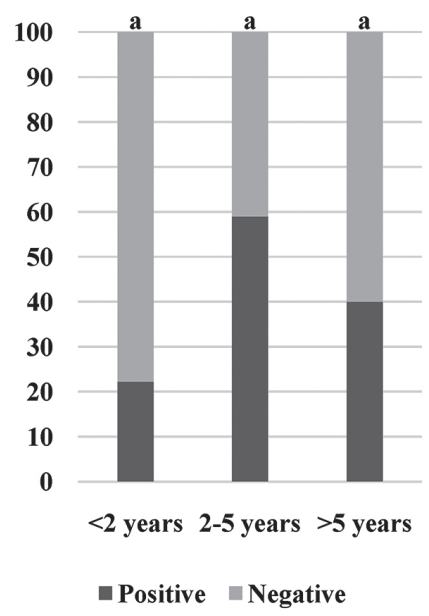

Figure 1. Ratios of positive/negative specimens (liver and lungs) for echinococcosis by age groups in cattle (A) and sheep (B). Significantly different values between the age groups are marked with different letters $(a, b)$

A

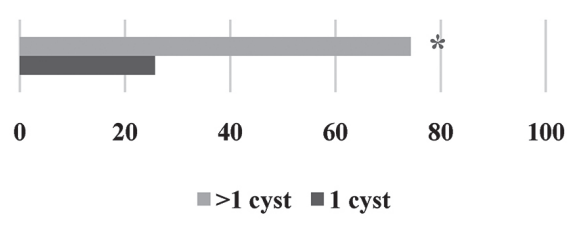

C

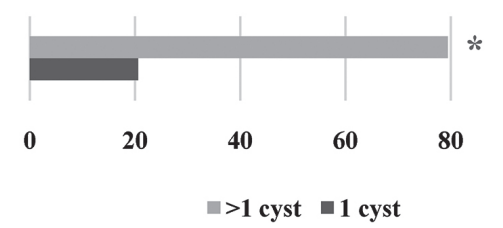

B

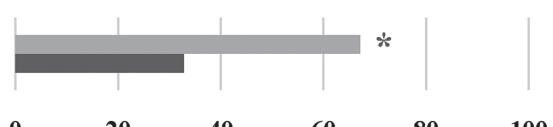

$\square \mathbf{1}$ cyst $\square 1$ cyst

D

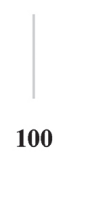

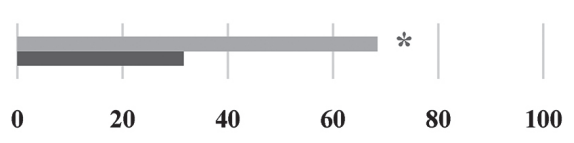

ㅁ1 cyst $\square 1$ cyst

Figure 2. Ratios between specimens with $>1$ or 1 cyst for cattle lungs (A), cattle liver (B), sheep lungs (C) and sheep liver (D). Significantly higher values are marked with '* 
A

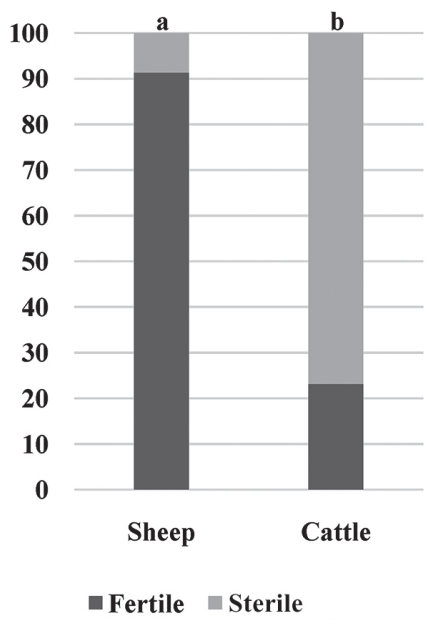

B

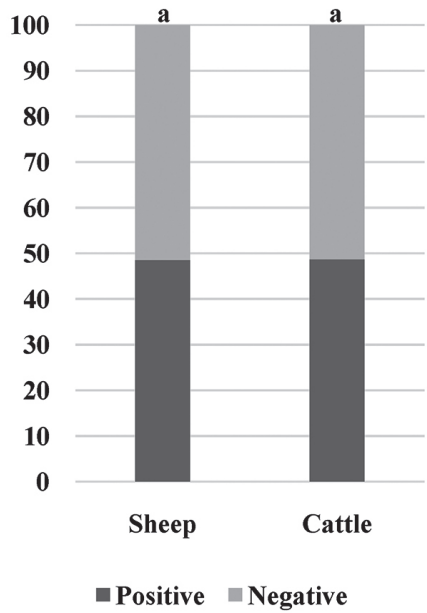

Figure 3. Ratios between sheep and cattle specimens: fertile or sterile cyst (A) and positive or negative on echinococcosis (B). Significantly different values between the animal species groups are marked with different letters $(a, b)$

A significantly higher number of fertile cysts were found in sheep specimens compared to cattle ( $91 \%$ vs. $23 \%$, respectively) (Fig. 3A). There was no significant difference between the number of positive sheep and cattle animals included in this study ( $49 \%$ vs. $49 \%$, respectively) (Fig. 3B).

\section{DISCUSSION}

This study indicates a high prevalence of echinococcosis in slaughtered cattle and sheep, which confirmed the endemic status of the disease in North Macedonia. According to the current research, the overall prevalence of echinococcosis was $60 \%$, higher than the prevalence reported in neighboring regions $(18,20,21,22)$ with no significant difference in the prevalence between cattle and sheep. The high prevalence in these animals can be related to the feeding system (especially grazing), which exposes them to contact with Echinococcus eggs as a result of the lack of dehelmintization of the dog population. In regard to the high prevalence rate, there are several other factors such as uncontrolled slaughtering with no supervision, inappropriate disposal of the infected organs, a large population of roaming dogs with access to livestock and carcasses, low awareness about the potential health risk, low education, and economic status of the population (16).

Diagnosis of echinococcosis in intermediate hosts is achieved by necropsy because the primary infection is always asymptomatic (24). The growth rate of the cysts is slow, from 1 to $5 \mathrm{~cm}$ per year, and the infected animals are slaughtered before the cysts cause clinical manifestation (25). According to the OIE (26), the control of the carcasses during slaughtering for the presence of Echinococcus cysts is an essential method that still remains the most common way of collecting data and assessment of echinococcosis prevalence. Post-mortem inspection of the internal organs in the slaughterhouses showed that the lungs and the liver were highly infected and more susceptible to echinococcosis. These findings were also demonstrated by Joanny et al. (27), Khan et al. (28), El-Dakhly et al. (29) and Kere et al. (30). The presence of a high number of cysts in the lungs and the liver may be due to specific intensive blood supply from the portal veins and hepatic arteries of the liver and soft consistency of the lung tissue that allows easy development of the cyst (10).

There was a significant correlation between the age of the livestock and the prevalence of echinococcosis, with the infection rate significantly increasing with the age of the animals (Fig. 1), which was also shown in other studies $(31,32)$. A study in Pakistan (28) shows that older animals can be 1.6 times more exposed to the risk of infection compared to younger animals. The main reason is lower immunological resistance and long exposure to the parasites that leads to increasing the size and the number of cysts per organ.

Cyst fluid showed high fertility in sheep, while in the cattle most of the cysts were sterile (Fig. 3). 
Similar results have been reported in Greece and Algeria $(33,34)$. Fertility of the cysts is an important indicator of which domestic ruminant type acts as a source for infection of the final hosts (35). The higher percent of fertile cysts in sheep, in contrast to cattle, indicates that sheep are the main reservoir and significant intermediate host in the lifecycle of Echinococcus spp. (10). On the other hand, the high percentage of sterile cysts in cattle suggests that cattle have no significant role in maintaining the life cycle of this parasite (36).

Different epidemiological conditions result in different echinococcosis prevalence rates. North Macedonia belongs to the countries with high echinococcosis prevalence in livestock. High numbers of Echinococcus cysts in the adult cattle and sheep indicate a long exposition to Echinococcus eggs with an increased possibility of infection or high contamination of the environment where the domestic ruminants are kept. The maintenance of the parasite lifecycle is closely related with the contact of dogs (as definitive host) with the offal from the intermediate host, as well as the easy access to the locations where animals are slaughtered. Hence, the slaughtering should be controlled and the infected organs should be confiscated and destroyed (37).

\section{CONCLUSION}

The high prevalence of echinococcosis in North Macedonia highlights the important role of the sheep in the life cycle of the disease because of the high number of fertile cysts. From a disease control perspective as well as prevention of echinococcosis, it is necessary to establish continuous surveys and monitoring systems of the epidemiological situation, especially in the endemic regions. The results of this research will provide the baseline data for implementing control programs and preventive measures. The measures should include control of backyard slaughtering, anthelmintic treatment of dogs, raising public awareness of this zoonosis, and most importantly secure disposal of the infected organs.

\section{CONFLICT OF INTEREST}

The authors declared that they have no potential conflict of interest with respect to the authorship and/or publication of this article.

\section{ACKNOWLEDGEMENTS}

This research was supported by the Faculty of Veterinary Medicine - Skopje, Ss. Cyril and Methodius University in Skopje.

\section{AUTHORS' CONTRIBUTION}

JS and AC conceived and designed the study. LjR and AC wrote the manuscript. LjR, AC, IC and JS performed the field and laboratory work. MN conducted the statistical analysis and participated in the interpretation of the results. All authors contributed to the final version of the manuscript.

\section{REFERENCES}

1. Otero-Abad, B., Torgerson, P.R. (2013). A systematic review of the epidemiology of echinococcosis in domestic and wild animals. PLoS Negl Trop Dis. 7(6): e2249.

https://doi.org/10.1371/journal.pntd.0002249

PMid:23755310 PMCid:PMC3674998

2. Budke, C.M., Casulli, A., Kern, P., Vuitton, D.A. (2017). Cystic and alveolar echinococcosis: Successes and continuing challenges. PLoS Negl Trop Dis. 11(4): e0005477. https://doi.org/10.1371/journal.pntd.0005477 PMid:28426657 PMCid:PMC5398475

3. Restrepo, A.M.C., Yang, Y.R., McManus, D.P., Gray, D.J., Giraudoux, P., Barnes, T.S., Williams, G.M., et al. (2016). The landscape epidemiology of echinococcosis. Infect Dis Poverty. 5(1): 1-13. https://doi.org/10.1186/s40249-016-0109-x PMid:26895758 PMCid:PMC4759770

4. Eckert, J., Deplazes, P. (2004). Biological, epidemiological, and clinical aspects of echinococcosis, a zoonosis of increasing concern. Clin Microbiol Rev. 17(1): 107-135. https://doi.org/10.1128/CMR.17.1.107-135.2004 PMid:14726458 PMCid:PMC321468

5. Romig, T., Deplazes, P., Jenkins, D., Giraudoux, P., Massolo, A., Craig, P.S., Wassermann, M., et al. (2017). Ecology and life cycle patterns of echinococcus species. Adv Parasitol. 95, 213-314. https://doi.org/10.1016/bs.apar.2016.11.002 PMid:28131364

6. Monteiro, K.M., de Carvalho, M.O., Zaha, A., Ferreira, H.B. (2010). Proteomic analysis of the Echinococcus granulosus metacestode during infection of its intermediate host. Proteomics 10(10): 1985-1999.

https://doi.org/10.1002/pmic.200900506

PMid:20217864 
7. Saeed, I., Kapel, C., Saida, L.A., Willingham, L., Nansen, P. (2000). Epidemiology of Echinococcus granulosus in Arbil province, Northern Iraq, 19901998. J Helminthol. 74(1): 83-88.

https://doi.org/10.1017/S0022149X00000111 PMid:10831057

8. Cardona, G.A., Carmena, D. (2013). A review of the global prevalence, molecular epidemiology and economics of cystic echinococcosis in production animals. Vet Parasitol. 192(1-3): 10-32.

https://doi.org/10.1016/j.vetpar.2012.09.027 PMid:23084536

9. Ahmadi, N.A., Meshkehkar, M. (2010). An abattoirbased study on the prevalence and economic losses due to cystic echinococcosis in slaughtered herbivores in Ahwaz, south-western Iran J Helminthol. 85(1): 33-39.

https://doi.org/10.1017/S0022149X10000234

PMid:20398435

10. Getaw, A., Beyene, D., Ayana, D., Megers, B., Abunna, F. (2010). Hydatidosis: Prevalence and its economic importance in ruminants slaughtered at Adama municipal abattoir, Central Oromia, Ethiopia. Acta Trop. 113(3): 221-225.

https://doi.org/10.1016/j.actatropica.2009.10.019 PMid:19883622

11. Ito, A. (2017). Review of "Echinococcus and Echinococcosis, Part A." edited by R.C. Andrew Thompson, Alan J. Lymbery and Peter Deplazes. Parasites Vectors 10, 408.

https://doi.org/10.1186/s13071-017-2345-8

PMid:28870244 PMCid:PMC5583985

12. Grosso, G., Gruttadauria, S., Biondi, A., Marventan, O.S., Mistretta, A. (2012). Worldwide epidemiology of liver hydatidosis including the Mediterranean area. World J Gastroenterol. 18(13): 1425-1437. https://doi.org/10.3748/wjg.v18.i13.1425 PMid:22509074 PMCid:PMC3319938

13. Mitrea, I.L., Ionita, M., Wassermann, M., Solcan, G., Romig, T. (2012). Cystic echinococcosis in Romania: an epidemiological survey of livestock demonstrates the persistence of hyperendemicity. Foodborne Pathog Dis. 9(11): 980-985. https://doi.org/10.1089/fpd.2012.1237 PMid:23075460

14. Derylo, A., Szilman, P. (1998). Prevalence of echinococcosis in swine, beef-cattle, ships and goats in Poland during 1996, 1997. Wiadomości Parazytologiczne 44(3): 413.
15. Carabin, H., Balsera-Rodriguez, F.J., Rebollar-Saenz, J., Benner, C.T., Benito, A., Fernandez-Crespo, J.C., Carmena, D. (2014). Cystic echinococcosis in the Province of Álava, North Spain: The monetary burden of a disease no longer under surveillance. PLoS Negl Trop Dis. 8(8): e3069. https://doi.org/10.1371/journal.pntd.0003069 PMid:25102173 PMCid:PMC4125306

16. Umhang, G., Richomme, C., Boucher, J. M., Hormaz, V., Boué, F. (2013). Prevalence survey and first molecular characterization of Echinococcus granulosus in France. Parasitol Res. 112(4): 1809-1812. https://doi.org/10.1007/s00436-012-3245-7 PMid:23271567 PMCid:PMC3597331

17. Alishani, M., Sherifi, K., Rexhepi, A., Hamidi, A., Armua-Fernandez, M.T., Grimm, F., Hegglin, D., Deplazes, P. (2017). The impact of socio-cultural factors on transmission of Taenia spp. and Echinococcus granulosus in Kosovo. Parasitology 144, 1736-1742.

https://doi.org/10.1017/S0031182017000750 PMid:28799892

18. Zuko, A., Obradović, Z. (2014). Echinococcosis in Bosnia and Herzegovina - an overview. ESCCAP Echinococcus meeting, Abstract booklet, October, 8-9, (p.21), Vilnius, Lithuania

19. Xhaxhiu, D., Kusi, I., Rapti, D., Kondi, E., Postoli, R., Rinaldi, L., Dimitrova, Z.M., et al. (2011). Principal intestinal parasites of dogs in Tirana, Albania. Parasitol Res. 108(2): 341-353. https://doi.org/10.1007/s00436-010-2067-8 PMid:20878182

20. Chaligiannis, I., Maillard, B., Ghalia, S., Markus, S., Anastasios, G., Bruno, S. (2015). Echinococcus granulosus infection dynamics in livestock of Greece. Acta Trop. 150, 64-70.

https://doi.org/10.1016/j.actatropica.2015.06.021 PMid:26123192

21. Breyer, I., Georgieva, D., Kurdova, R., Gottstein, B. (2004). Echinococcus granulosus strain typing in Bulgaria: The G1 genotype is predominant in intermediate and definitive wild hosts. Parasitol Res. 93(2): 127-130.

https://doi.org/10.1007/s00436-004-1116-6

PMid:15127295

22. Bobic, B., Nikolic, A., Katic Radivojevic, S., Klun, I., Djurkovic-Djakovic, O. (2012). Echinococcosis in Serbia: An Issue for the 21st Century? Foodborne Pathog Dis. 9(11): 967-73.

https://doi.org/10.1089/fpd.2012.1227 PMid:23113724 
23. Daryani, A., Sharif, M., Amouei, A., Nasrolahei, M. (2009). Fertility and viability rates of hydatid cysts in slaughtered animals in the Mazandaran Province, Northern Iran. Trop Anim Health Prod. 41(8): 1701-1705. https://doi.org/10.1007/s11250-009-9368-x PMid:19455399

24. Craig, P., Mastin, A., Kesteren, F., Boufana, B. (2015). Echinococcus granulosus: Epidemiology and state-of-the-art of diagnostics in animals. Vet Parasitol. 213(3): 132-148.

https://doi.org/10.1016/j.vetpar.2015.07.028 PMid:26321135

25. Abdulhameed, M.F. (2018). The epidemiology and impact of cystic echinococcosis in humans and domesticated animals in Basrah Province, Iraq. Doctoral dissertation, Murdoch University

26. World Organisation for Animal Health (OIE) (2021). Echinococcosis (infection with Echinococcus granulosus and with E. multilocularis) manual of diagnostic tests and vaccines for terrestrial animals. Chapter 3.1.6. OIE, Paris.

27. Joanny, G., Cappai, M.G., Nonnis, F., Tamponi, C., Dessì, G., Mehmood, N., Dahdah, J., et al. (2021). Human cystic echinococcosis in Lebanon: A retrospective study and molecular epidemiology. Acta Parasit. 1-10.

https://doi.org/10.1007/s11686-021-00453-w PMid:34264443

28. Khan, S.N., Ali, R., Khan, S., Norin, S., Rooman, M., Akbar, N.U., Khan, T.A., et al. (2021). Cystic echinococcosis: an emerging zoonosis in southern regions of Khyber Pakhtunkhwa, Pakistan. BMC Vet Res. 17(1): 1-11.

https://doi.org/10.1186/s12917-021-02830-Z

PMid:33794898 PMCid:PMC8015088

29. El-Dakhly, K.M., Arafa, W.M., El-Nahass, E.N., Shokier, K.A.M., Noaman, A.F. (2019). The current prevalence and diversity of cystic echinococcosis in slaughtered animals in Egypt. J Parasit Dis. 43(4): 711-717.

https://doi.org/10.1007/s12639-019-01151-1

PMid:31749543 PMCid:PMC6841774

30. Kere, O.J., Joseph, E., Jessika, B.L., Maina, K.J. (2019). Prevalence and monetary loss due to cystic Echinococcosis in slaughterhouse livestock: A case study of Migori County, Kenya. Parasite Epidemiol. Control 5: e00105.

https://doi.org/10.1016/j.parepi.2019.e00105

PMid:31193569 PMCid:PMC6536491
31. Rinaldi, L., Maurelli, M.P., Capuano, F., Perugini, A.G., Veneziano, V., Cringoli, S. (2008). Molecular update on cystic echinococcosis in cattle and water buffaloes of Southern Italy. Zoonoses Public Health 55(2): 119-123.

https://doi.org/10.1111/j.1863-2378.2007.01101.x

PMid:18234031

32. Zelalem, F., Tadele, T., Nigussie, Z., Macias, C., Kebede, N. (2012). Prevalence and characterization of hydatidosis in animals slaughtered at Addis Ababa abattoir, Ethiopia. J Parasitol Vector Biol. 4(1): 1-6.

33. Founta, A., Chliounakis, S., Antoniadou Sotiriadou, K., Koidou, M., Bampidis, V. (2016). Prevalence of hydatidosis and fertility of hydatid cysts in food animals in Northern Greece. Vet Ital. 52(2): 123-127.

34. Kouidri, M., Benchaib-Khoudja, F., Boulkaboul, A., Selles, S.M.A. (2013). Cystic echinococcosis in small ruminants in Tiaret (Algeria). Glob Vet. 11(6): 753-758.

35. Almalki, E., Al-Shaebi, E.M., Al-Quarishy, S., El-Matbouli, M., Abdel-Baki, A.S. (2017). In vitro effectiveness of Curcuma longa and Zingiber officinale extracts on Echinococcus protoscoleces. Saudi J Biol Sci. 24(1): 90-94. https://doi.org/10.1016/j.sjbs.2016.05.007 PMid:28053576 PMCid:PMC5198992

36. Kebede, W., Hagos, A., Girma, Z., Lobago, F. (2009). Echinococcosis/hydatidosis: its prevalence, economic and public health significance in Tigray region, North Ethiopia. Trop Anim Health Prod. 41(6): 865-871.

https://doi.org/10.1007/s11250-008-9264-9

PMid:19002598

37. Thompson, R.C.A. (1995). Biology and systematics of Echinococcus. In R.C.A. Thompson, A.J. Lymbery (Eds.), The biology of Echinococcus and hydatid disease (pp. 1-50). Wallingford: CAB International 